\title{
Lung cancer in Victoria: are we making progress?
}

Paul L R Mitchell MB ChB, FRACP, MD Medical Oncologist

Vicky J Thursfield BSc, GradDipAppStat, Cancer Control Information Manager, Victorian Cance Registry $^{2}$

David L Ball MD, FRANZCR Radiation Oncologist

Gary E Richardson MB BS, FRACP Director $^{4}$

Louis B Irving MB BS, FRACP, FRACGP Director, Department of Respiratory and Sleep Medicine

Yvonne Torn-Broers BA(Hons),

Clinical Surveys Manager

Graham G Giles BSc, Msc, PhD, Epidemiologist, Cance Control Research Division

\section{Gavin M Wright}

MB BS, FRACS

Director of Surgical Oncology and Surgeon

1 Olivia Newton-John Cancer and Wellness Centre, Austin Health, Melbourne, VIC

2 Cancer Council Victoria Melbourne, VIC

3 Peter MacCallum Cancer Centre, Melbourne, VIC

4 Cabrini Academic Haematology and Oncology Service, Cabrini Hospital, Melbourne, VIC

5 Royal Melbourn Hospital, Melbourne, Vic

6 University of Melbourne Department of Surgery.

St Vincent's Hospital, Melbourne, Vic

paul.mitchell@ austin.org.au

MJA 2013; 199: 674-679 doi: 10.5694/mjal3.10331

Editorial p 639 Online first 28/10/13 ung cancer is the greatest single cause of cancer death in Australia for both men and women. ${ }^{1,2}$ Despite Australia having some of the best outcomes internationally, the 5-year relative survival rate is less than $15 \%$. $^{2,3}$

Our previously reported survey of cases of lung cancer, reported to the Victorian Cancer Registry in the first half of 1993, identified opportunities to improve patient management. ${ }^{4,5}$ Since that time, there have been a number of important developments in staging and treatment for this disease. ${ }^{6-8}$

In this study, 10 years on, we present the results of a detailed survey of Victorian patients who presented with lung cancer in 2003 and who were followed for 5 years to provide updated and additional information, including changes over the decade.

\section{Methods}

We surveyed all people who were diagnosed with lung cancer from 1 January to 30 June 2003 and identified by the Victorian Cancer Registry; postmortem diagnoses were excluded. Ethics approval was obtained from the Cancer Council Victoria Institutional Ethics Committee. A questionnaire relating to management was sent to the treating clinicians, and non-responding clinicians were actively followed up to obtain data. Comorbid conditions were scored according to the Colinet simplified comorbidity score. ${ }^{9}$ Statistical analysis was performed using SPSS, version 14.0, release 14.0.2 (SPSS Inc). Overall survival was estimated using actuarial methods, and 5 -year survival proportions with 95\% CIs are shown. Multivariate analysis to determine the effect of prognostic and treatment factors on survival was carried out using Cox proportional hazards regression analysis. \begin{abstract}
Objectives: To identify areas to improve patient management in lung cancer, which remains the greatest cause of death from cancer in Australia.

Design and setting: Retrospective survey of all cases of lung cancer reported to the Victorian Cancer Registry from 1 January to 30 June 2003 and followed up for
\end{abstract} 5 years.

Main outcome measures: Patient and disease characteristics, investigations, staging, treatment, cause of death, survival.

Results: 841 patients were included. Smoking data were available for 799, of whom 63 (7.9\%) had never smoked. Of 655 non-small cell lung cancer (NSCLC) cases, 198 (30.2\%) were treated with curative intent, 125 (19.1\%) by surgery and $73(11.1 \%)$ by radiotherapy with or without chemotherapy. Only $7(6.9 \%)$ of surgical patients with complete $\mathrm{R}_{0}$ resection had adjuvant chemotherapy. Of 101 small cell lung cancer (SCLC) cases, a third had limited stage disease which was mostly treated with curative intent by chemotherapy with or without radiotherapy. Patients whose cases were discussed at a multidisciplinary meeting (MDM) were significantly more likely to receive anticancer treatment and had longer survival; on multivariate analysis, MDM discussion was an independent prognostic factor. Compared with a similar survey 10 years earlier, the median age of patients diagnosed with lung cancer had increased by almost 3 years, the proportion of affected men decreased and adenocarcinoma was more frequent, while $10 \%$ of patients continued to have no pathologically confirmed diagnosis and $26 \%$ continued to receive no anticancer treatment. The number of patients with NSCLC who went on to a definitive surgical procedure fell with no detriment to survival, which likely reflected better staging with the introduction of positron emission tomography scanning.

Conclusions: Opportunities to improve patient management included increasing the proportion with a pathologically confirmed diagnosis and greater use of postsurgical adjuvant chemotherapy. A high proportion of patients received no treatment, with underuse of chemotherapy and radiotherapy. Critically, the low rate of case discussions at MDMs needs to increase. However, effective strategies are required to identify cases early, as over two-thirds currently present with incurable disease.

\section{Results}

Nine hundred and twenty-one eligible cases were reported and 841 $(91.3 \%)$ were included in the survey. Reasons for cases not being included were: doctor refusing or being unavailable (48); record unavailable (21); and other (11). The characteristics of the 841 patients are shown in Box 1 . For 194 patients (23.1\%), lung cancer was diagnosed in the absence of symptoms, mostly as a result of imaging performed for other reasons. Only 16 patients $(1.9 \%)$ were diagnosed by a screening chest $x$-ray and/or computed tomography scan. Thirty-three patients $(3.9 \%)$ were recruited to a clinical trial.

\section{Non-small cell lung cancer}

The characteristics and management of the 655 patients with non-small cell lung cancer (NSCLC) are shown in Box 2 and Box 3. Weight loss was evident in 270 patients (43.8\%), and $87(14.1 \%)$ had lost more than $10 \%$ of their bodyweight.

Treatment was considered to have had curative intent based on the information available in the health records, despite no apparent curative treatment being given to six patients with NSCLC. Of the 125 patients treated surgically with curative intent, 97 (77.6\%) underwent positron emission tomography (PET) scanning before surgery. All but eight of the 23 patients who did not have a 
1 Characteristics of 841 patients with lung cancer

\begin{tabular}{lc} 
Characteristic & No. \\
\hline Sex & $531(63.1 \%)$ \\
Male & $310(36.9 \%)$ \\
Female & 72 years \\
Median age (range) & $(30-94$ years) \\
Smoking* & \\
Never & $63(7.9 \%)$ \\
Past & $458(57.3 \%)$ \\
Current & $278(34.8 \%)$ \\
Unknown & $42(5.0 \%)$ \\
Tissue diagnosis obtained & \\
Yes & $756(89.9 \%)$ \\
Cytology alone & $164(21.7 \%)$ \\
Histology & $592(78.3 \%)$ \\
No & $85(10.1 \%)$ \\
Diagnosis & \\
NSCLC & $655(86.6 \%)$ \\
SCLC & $101(13.4 \%)$ \\
Comorbidity (Colinet simplified \\
comorbidity score)* \\
0-2 & $75(9.4 \%)$ \\
$3-5$ & $7(0.9 \%)$ \\
$6-8$ & $425(53.2 \%)$ \\
$9-11$ & $196(24.5 \%)$ \\
$12-14$ & $83(10.4 \%)$ \\
$15+$ & $13(1.6 \%)$ \\
Unavailable & $42(5.0 \%)$ \\
\hline & \\
\hline &
\end{tabular}

NSCLC $=$ Non-small cell lung cancer SCLC = Small cell lung cancer.

* Percentages shown are of cases for whom status is known.

PET scan had Stage I disease. Adjuvant chemotherapy was administered to seven patients of the 101 with complete $\left(\mathrm{R}_{0}\right)$ resections, including two of 21 with Stage II-IIIA disease and two of 25 with Stage IB disease. Of the 24 patients who had incomplete $\left(\mathrm{R}_{1}\right.$ or $\left.\mathrm{R}_{2}\right)$ resections $\left(\mathrm{R}_{1}, 23 ; \mathrm{R}_{2}\right.$, $1), 18$ received additional treatment: this was radiotherapy alone for 11 patients and chemoradiotherapy for seven.

Fifty-three of the 73 patients treated with radiotherapy with curative intent also received chemotherapy, which was concurrent for 26 patients and sequential for two, while the schedule was unknown for 25. A PET scan was performed before curative radiotherapy for 61 (83.6\%).

Chemotherapy was administered at some time, with curative or palliative intent, to 258 (39.4\%) patients with NSCLC, and radiotherapy to 365 (55.7\%).
The median survival time for patients with NSCLC was 6.9 months (SE, 0.42 months) with a 5year crude survival rate of $10.8 \%$. The median and 5-year survivals for patients treated with curative intent by surgery were 45 months (SE, 4.4 months) and $43.2 \%$, respectively, and by radiotherapy or chemoradiotherapy 14.8 months (SE, 4.6 months) and $19 \%$, respectively, while the median survival time with palliative treatment was 5.7 months and, with no active treatment, 4 months $(P<0.001)$. Most patients died from their lung cancer, but the cause of death was not the index lung cancer for 44 patients $(6.7 \%)$, while for five $(0.8 \%)$, the cause of death was unknown.

\section{Small cell lung cancer}

The characteristics and management of the 101 patients with small cell lung cancer (SCLC) are detailed in Box 2 and Box 3 . The median survival time for patients with SCLC was 7.2 months (SE, 0.96 months) with three patients $(3.0 \%)$ surviving 5 years. Patients treated with curative intent had a median survival time of 12.8 months (SE, 6.0 months) and a 5year survival rate of $11.1 \%$. The cause of death was not the index lung cancer for five patients $(5 \%)$, while for one, the cause of death was unknown.

\section{Clinical diagnosis only}

The characteristics and management of the 85 patients with a clinical diagnosis (CD) only of lung cancer are detailed in Box 2 and Box 3. For 53, there was an attempt to obtain a pathologically confirmed diagnosis by cytological examination of sputum, bronchoscopy or biopsy.

Patients with CD only, when compared with those with a diagnosis confirmed by pathology testing, were older (median age, 79 years v 71 years; $P<0.001$ ), had a lower Eastern Cooperative Oncology Group (ECOG) performance status (PS) score $(0-1,13 \%$ v $51 \% ; P<0.001)$, and were less likely to be referred to a specialist $(83.5 \%$ v $99.1 \%, P<0.001)$ or discussed at a multidisciplinary meeting (MDM; 11\% v 30\%; P= 0.001), less likely to be treated with curative intent $(2 \%$ v $31 \% ; P<0.001)$,
2 Patient and disease characteristics for 841 cases of nonsmall cell, small cell and clinically diagnosed lung cancer

\begin{tabular}{|c|c|c|c|}
\hline Characteristic & NSCLC & SCLC & CD \\
\hline No. of patients & 655 & 101 & 85 \\
\hline \multicolumn{4}{|l|}{ Sex } \\
\hline Male & $418(63.8 \%)$ & $64(63.4 \%)$ & 46 \\
\hline Female & 237 (36.2\%) & $37(36.6 \%)$ & 39 \\
\hline $\begin{array}{l}\text { Median age in years } \\
\text { (range) }\end{array}$ & $71(30-94)$ & $69(35-90)$ & $79(46-92)$ \\
\hline Symptomatic* & $502(76.6 \%)$ & $80(79.2 \%)$ & 57 \\
\hline \multicolumn{4}{|l|}{$\begin{array}{l}\text { ECOG performance status } \\
\text { score }^{\dagger}\end{array}$} \\
\hline $0-1$ & $331(63.3 \%)$ & $56(66.7 \%)$ & 11 \\
\hline 2 & $88(16.8 \%)$ & $11(13.1 \%)$ & 10 \\
\hline $3-4$ & $104(19.9 \%)$ & $17(20.2 \%)$ & 48 \\
\hline Weight loss ${ }^{\ddagger}$ & $270(43.8 \%)$ & $52(54.7 \%)$ & 40 \\
\hline \multicolumn{4}{|l|}{ Staging investigations } \\
\hline CT thorax & $622(95.0 \%)$ & $97(96.0 \%)$ & 73 \\
\hline PET scan & $283(43.2 \%)$ & $13(12.9 \%)$ & 7 \\
\hline Bronchoscopy & $388(59.2 \%)$ & $60(59.4 \%)$ & 15 \\
\hline Guided lung biopsy & $244(37.3 \%)$ & $20(19.8 \%)$ & 3 \\
\hline Mediastinal procedure & $51(7.8 \%)$ & $10(9.9 \%)$ & 0 \\
\hline \multicolumn{4}{|l|}{ Morphology } \\
\hline Adenocarcinoma & 261 (39.8\%) & - & - \\
\hline Squamous cell & $152(23.2 \%)$ & - & - \\
\hline Large cell & $82(12.5 \%)$ & - & - \\
\hline $\begin{array}{l}\text { Bronchioloalveolar } \\
\text { carcinoma }\end{array}$ & $11(1.7 \%)$ & - & - \\
\hline Undifferentiated/other & 149 (22.8\%) & - & - \\
\hline \multicolumn{4}{|l|}{ Stage $^{\S}$} \\
\hline 1 & $107(17.7 \%)$ & - & 5 \\
\hline IA & $61(10.1 \%)$ & & \\
\hline IB & $46(7.6 \%)$ & & \\
\hline ॥ & $30(5.0 \%)$ & - & 3 \\
\hline$\| A$ & $2(0.4 \%)$ & & \\
\hline IIB & $28(4.6 \%)$ & & \\
\hline III & 156 (25.8\%) & - & 12 \\
\hline IIIA & 71 (11.8\%) & & \\
\hline IIIB & $85(14.0 \%)$ & & \\
\hline IV & 311 (51.5\%) & - & 46 \\
\hline \multicolumn{4}{|l|}{ Extent of disease $(\mathrm{SCLC})^{\S}$} \\
\hline Limited & - & $33(33.3 \%)$ & - \\
\hline Extensive & - & $66(66.7 \%)$ & - \\
\hline
\end{tabular}

$\mathrm{CD}=$ clinically diagnosed. $\mathrm{CT}=$ computed tomography. $\mathrm{ECOG}=$ Eastern Cooperative Oncology Group. NSCLC = non-small cell lung cancer. $\mathrm{PET}=$ positron emission tomography. $\mathrm{SCLC}=$ small cell lung cancer. * Symptomatic presentation data not available for eight patients with * Symptomatic presentation data not available for eight patients with
NSCLC. † Performance status (PS) data not available for 132 NSCLC, 17 SCLC and 16 CD patients. $¥$ Weight loss data not available for 38 patients with NSCLC, 6 patients with SCLC and 19 patients with CD. $\$$ Staging data not available for 51 patients with NSCLC, 2 patients with SCLC and 19 CD patients.

Percentages shown are of cases for whom PS, weight loss or stage are known.

and more likely to receive no anticancer therapy $(84 \%$ v $20 \% ; P<0.001)$. Patient outcomes were worse for the CD cohort, with a median survival time of 1.1 months (SE, 0.2 months) $\mathrm{v}$ 6.9 months (SE, 0.4 months) $(P<0.001)$; 56 CD patients $(66 \%)$ died within 2 months of diagnosis. 
3 Management and initial treatment of 841 cases of non-small cell, small cell and clinically diagnosed lung cancer

\begin{tabular}{|c|c|c|c|}
\hline Management & NSCLC & SCLC & $C D$ \\
\hline No. of patients & 655 & 101 & 85 \\
\hline \multicolumn{4}{|l|}{ Specialist referral before treatment } \\
\hline Any & $649(99.1 \%)$ & $100(99.0 \%)$ & 71 \\
\hline Medical oncologist & 386 (58.9\%) & $82(81.2 \%)$ & 28 \\
\hline Thoracic surgeon & 304 (46.4\%) & $27(26.7 \%)$ & 10 \\
\hline Respiratory physician & $301(46.0 \%)$ & $41(40.6 \%)$ & 23 \\
\hline Radiation oncologist & $253(38.6 \%)$ & $20(19.8 \%)$ & 14 \\
\hline Palliative care & $33(5.0 \%)$ & $7(6.9 \%)$ & 10 \\
\hline Multidisciplinary case discussion* & $206(33.0 \%)$ & $19(20.9 \%)$ & 9 \\
\hline \multicolumn{4}{|l|}{ Initial treatment } \\
\hline No treatment & $138(21.1 \%)$ & $9(8.9 \%)$ & 71 \\
\hline Curative intent & $198(30.2 \%)$ & $27(26.7 \%)$ & 2 \\
\hline Surgery & 125 (19.1\%) & $1(1.0 \%)$ & - \\
\hline \multicolumn{4}{|l|}{ Lobectomy with: } \\
\hline Additional surgery & 82 & & \\
\hline Pneumonectomy & 16 & & \\
\hline Segmental resection & 27 & & \\
\hline Radiotherapy & $73(11.1 \%)$ & $20(19.8 \%)$ & 2 \\
\hline Radiotherapy alone & 20 & - & 1 \\
\hline Chemoradiotherapy & 53 & 20 & 7 \\
\hline Chemotherapy alone & - & $7(6.9 \%)$ & \\
\hline Palliative intent & 319 (48.7\%) & $65(64.4 \%)$ & 12 \\
\hline Surgery & $74(23.8 \%)$ & $5(5.0 \%)$ & 2 \\
\hline Radiotherapy & $203(65.3 \%)$ & 11 (10.9\%) & 10 \\
\hline Thoracic & 136 & & \\
\hline Metastases & 89 & & \\
\hline Chemotherapy & $147(47.3 \%)$ & $63(62.4 \%)$ & 2 \\
\hline
\end{tabular}

$\mathrm{CD}=$ clinically diagnosed. $\mathrm{NSCLC}=$ Non-small cell lung cancer. $\mathrm{SCLC}=$ Small cell lung cancer * Data not available for 30 NSCLC, 10 SCLC and 4 CD cases. Percentages shown are of cases with known data.

\section{No treatment}

Overall, 218 patients (25.9\%) received no treatment, including 138 with NSCLC, nine with SCLC and 71 with CD only (Box 3). The median age for these patients was 76 years and the median survival time was 1.1 months. Treatment was offered to, but declined by, 55 patients $(25.2 \%$ of those receiving no treatment).

Reasons for 163 patients not being offered therapy included comorbid conditions (101); poor performance status (86); rapid deterioration or death by 2 months (103); age (24); absence of symptoms (20); and travel distance (two). The cohort of 163 patients not offered therapy and for whom data were available included some who might have benefited from therapy, including $12(7.4 \%)$ with stage I/II disease, $74(45.4 \%)$ with ECOG PS scores of $0-2,37(22.7 \%)$ with low Colinet simplified comorbidity scores of $0-6$, and 9 (5.5\%) who had never smoked.

\section{Smoking}

Among 799 patients with available data on smoking, 63 (7.9\%) had never smoked. Overall, 45 of the 63 who had never smoked (71\%) were women. Thus, a much higher proportion of women $(15.3 \%$; 45 of 294$)$ than men $(3.6 \%$; 18 of 505$)$ had never smoked $(P<0.001)$. Previous smokers had stopped smoking a median of 12 years earlier. Among all smokers, the median pack-years (PY) was 50, and there was a significant difference by sex in smoking exposure at the time lung cancer was diagnosed, with a median of $37 \mathrm{PY}$ for women and 52 for men $(P<0.001)$.

For NSCLC, there was a trend for fewer current smokers to present with early-stage disease, with 35 of $203(17.2 \%)$ presenting with Stage I/ II disease compared with 13 of 50 of those who had never smoked (26\%) and 87 of 335 previous smokers (26\%) $(P=0.057)$.

Among all patients with lung cancer, 55 of the 63 who had never smoked $(87.3 \%)$ died within 5 years of diagnosis, 51 of lung cancer and four (6.4\%) from other causes. The proportion of current and ex-smokers dying from causes other than the index lung cancer was similar: 12 of $278(4.3 \%)$ and 31 of $458(6.8 \%)$, respectively.

\section{Analysis by cancer network and urban/rural location}

There was no significant difference between the Melbourne-based and the regional/rural cancer networks (integrated cancer services [ICSs]) in frequency of diagnoses obtained by pathology testing, cancer stage and ECOG PS at presentation, use of PET scan staging, or the proportion of patients receiving treatment. When adjusted for age and sex, there was no difference in survival between metropolitan and regional/rural areas. However, on multivariate analysis, ICS was significant in the model and survival for two regional/rural ICSs (Loddon Mallee and Grampians) was significantly worse (Box 4).

\section{Case presentation at multidisciplinary meetings}

Patients discussed at multidisciplinary meetings (MDMs), compared with those not discussed, were younger (median age, 69 v 73 years; $P<0.001$ ), more likely to be treated with curative intent (103 of 234 [44.0\%] v 125 of 563 [22.2\%]; $P<0.001)$, had a better ECOG PS score (0-1, 141 of 204 [69.1\%] v 241 of 437 [55.2\%]; $P<0.001)$ and earlier cancer stage (I/II or limited, 67 of 218 [30.7\%] v 106 of 511 [20.7\%]; $P=0.004$ ).

Patients whose cases were discussed at an MDM were more likely to receive active treatment (190 of 233 [81.6\%] v 397 of 563 [70.5\%]; $P=$ $0.004)$ and had improved survival (10.8 months v 5.5 months; $P<0.001)$. As early death may have prevented case discussion, a landmark analysis (an analysis at a point in time) was carried out including only those surviving for 2 months or longer, which also showed a significant benefit (13.3 months v 9.3 months; $P<0.001)$. A multivariate 
survival analysis was carried out including the variables shown to be significant (see below and Box 4). In this analysis, discussion at MDMs remained an independent prognostic factor for improved survival for both all lung cancer $(P=0.008)$ and $\operatorname{NSCLC}(P=0.005)$.

\section{Survival analysis}

Cox proportional hazards regression was carried out for risk of death (Box 4). Included variables were: age, sex, type of cancer, cancer stage, weight loss, ECOG PS, Colinet simplified comorbidity score, smoking by lifetime PY, region of birth, urban place of residence, ICS of usual residence and socioeconomic status (based on residence). By multivariate analysis the following were significant: ECOG PS, cancer stage, sex, type of cancer, smoking by lifetime PY, weight loss, region of birth and ICS of usual residence. We also performed the analysis for patients with NSCLC. The following were significant: age; ECOG PS; weight loss; cancer stage; and smoking by lifetime PY. For SCLC, only ECOG PS and cancer stage were significant.

The analysis was repeated with treatment modalities included. The following variables were significant for NSCLC: ECOG PS, cancer stage, smoking by lifetime PY, surgery, and chemotherapy, while weight loss was of borderline significance. For SCLC, ECOG PS, cancer stage and chemotherapy were significant.

\section{Comparisons between 2003 and 1993 survey results}

Box 5 shows that the median age at diagnosis had increased by 34 months over the 10 years since the previous survey. ${ }^{4}$ This compares with a 10month increase in age for all cancers over the previous decade (data not shown $)(P<0.001)$. There was no significant change in survival when adjusted for age.

\section{Discussion}

In this study we were able to obtain data for over $90 \%$ of reported cases which is a high proportion compared with some other studies. ${ }^{10}$ Although $92.1 \%$ of patients had smoked, only a third were current smokers. For
4 Multivariate survival analysis of lung cancer in Victoria showing variables in the equation after iterative inclusion and removal

\begin{tabular}{|c|c|c|c|c|}
\hline Variables & $\operatorname{Exp}(B) *$ & $B^{\dagger}$ & SE & $P$ \\
\hline ECOG performance status & & & & $<0.001$ \\
\hline Fully active & & 1.00 & & \\
\hline Limited activity & 1.33 & 0.29 & 0.14 & 0.039 \\
\hline Bed $<50 \%$ of day & 1.82 & 0.60 & 0.16 & $<0.001$ \\
\hline Bed $>50 \%$ of day & 3.07 & 1.12 & 0.16 & $<0.001$ \\
\hline Bed-bound & 5.22 & 1.65 & 0.21 & $<0.001$ \\
\hline Unknown & 1.67 & 0.51 & 0.15 & 0.001 \\
\hline Extent of disease & & & & $<0.001$ \\
\hline Limited (Stage I, II, III) & 1.00 & & & \\
\hline Extensive (Stage IV) & 3.01 & 1.10 & 0.11 & $<0.001$ \\
\hline Unknown stage & 2.44 & 0.89 & 0.16 & $<0.001$ \\
\hline \multicolumn{5}{|l|}{ Sex } \\
\hline Male & 1.00 & & & \\
\hline Female & 0.81 & -0.21 & 0.08 & 0.009 \\
\hline Cell type & & & & $<0.001$ \\
\hline NSCLC & 1.00 & & & \\
\hline SCLC & 1.38 & 0.32 & 0.11 & 0.004 \\
\hline No pathologically confirmed diagnosis & 1.70 & 0.53 & 0.14 & $<0.001$ \\
\hline Smoking category & & & & 0.013 \\
\hline Never smoked & 1.00 & & & \\
\hline$<40$ pack years & 1.07 & 0.07 & 0.17 & 0.676 \\
\hline 40-80 pack years & 1.15 & 0.14 & 0.16 & 0.365 \\
\hline$>80$ pack years & 1.29 & 0.26 & 0.19 & 0.179 \\
\hline Not known & 1.47 & 0.38 & 0.16 & 0.013 \\
\hline Weight loss & & & & 0.004 \\
\hline None & 1.00 & & & \\
\hline$<10 \%$ of weight & 1.04 & 0.04 & 0.12 & 0.744 \\
\hline$>10 \%$ of weight & 1.23 & 0.21 & 0.11 & 0.059 \\
\hline Amount of loss not known & 1.50 & 0.41 & 0.11 & $<0.001$ \\
\hline Not known & 1.28 & 0.24 & 0.15 & 0.099 \\
\hline Region of birth & & & & 0.011 \\
\hline Australia & 1.00 & & & \\
\hline United Kingdom & 1.22 & 0.20 & 0.12 & 0.097 \\
\hline Northern and eastern Europe & 1.19 & 0.18 & 0.16 & 0.261 \\
\hline Southern Europe & 0.99 & -0.01 & 0.12 & 0.964 \\
\hline Asia & 0.63 & -0.45 & 0.22 & 0.035 \\
\hline Other & 0.81 & -0.22 & 0.23 & 0.347 \\
\hline Not known & 0.23 & -1.46 & 0.59 & 0.013 \\
\hline ICS of usual residence & & & & 0.039 \\
\hline Southern Melbourne & 1.00 & & & \\
\hline Western and central Melbourne & 1.13 & 0.12 & 0.11 & 0.286 \\
\hline North-eastern Melbourne & 1.01 & 0.01 & 0.11 & 0.954 \\
\hline Barwon & 1.22 & 0.20 & 0.14 & 0.165 \\
\hline Grampians & 1.69 & 0.53 & 0.20 & 0.008 \\
\hline Loddon Mallee & 1.39 & 0.33 & 0.15 & 0.034 \\
\hline Hume & 0.86 & -0.15 & 0.18 & 0.409 \\
\hline Gippsland & 1.24 & 0.21 & 0.16 & 0.176 \\
\hline
\end{tabular}

ECOG = Eastern Cooperative Oncology Group. ICS = Integrated Cancer Service. NSCLC = Non-small cell lung cancer. SCLC = Small cell lung cancer.

* Hazard ratio for risk of death for each level of factor compared with reference category. $\dagger$ Regression coefficient. 


\section{Lung cancer in Victoria: 2003 compared with 1993}

\begin{tabular}{lcc} 
Characteristic & 1993 & 2003 \\
\hline No. of patients & 868 & 841 \\
Median age (years) & 69 years & 72 years \\
Sex & & \\
$\quad$ Male & $609(70.2 \%)$ & $531(63.1 \%)$ \\
$\quad$ Female & $259(29.8 \%)$ & $310(36.9 \%)$ \\
Cancer type & & \\
NSCLC & $635(73.2 \%)$ & $655(77.9 \%)$ \\
Adenocarcinoma & $204(32.1 \%)$ & $278(42.4 \%)$ \\
Squamous & $269(42.4 \%)$ & $152(23.2 \%)$ \\
SCLC & $124(14.3 \%)$ & $101(12.0 \%)$ \\
Diagnosis & & \\
By cytological test only* & $135(17.7 \%)$ & $163(21.6 \%)$ \\
$\quad$ No tissue diagnosis & $107(12.3 \%)$ & $85(10.1 \%)$ \\
Treatment & & \\
No treatment & $215(24.8 \%)$ & $218(25.9 \%)$ \\
NSCLC curative surgery ${ }^{\dagger}$ & $161(25.4 \%)$ & $125(19.1 \%)$ \\
NSCLC multimodality treatment ${ }^{\ddagger}$ & $46(22.2 \%)$ & $78(39.4 \%)$ \\
\hline
\end{tabular}

NSCLC $=$ Non-small cell lung cancer. $\mathrm{SCLC}=$ Small cell lung cancer. * Percentage for cytological diagnosis as a percentage of all cases with a pathologically confirmed diagnosis. † Percentage is of all NSCLC cases. $\ddagger$ Percentage of patients with NSCLC receiving curative treatment.

smokers with lung cancer, exposure to tobacco, as indicated by pack years, was $29 \%$ less for women, which is consistent with the previously reported observation that women are more susceptible to carcinogens in tobacco smoke. $^{11}$

There was no pathologically confirmed diagnosis for $10.1 \%$ of Victorian patients, which was a lower percentage than in New South Wales, Queensland, New Zealand and the United Kingdom. ${ }^{10,12-14}$ Patients with no pathologically confirmed diagnosis had a median survival time of just over a month, and very few received treatment. It is unclear if any of these patients might have benefited from treatment, and some may have had non-malignant but fatal conditions such as tuberculosis.

Of all Victorian patients with lung cancer, $97.5 \%$ (820 of 841$)$ were referred to a specialist before treatment, which is considerably higher than in NSW, Scotland and New Zealand. ${ }^{10,13,15}$ Although initial referrals to palliative care physicians were infrequent, over $40 \%$ of cases later involved palliative care physicians. The proportion of all cases discussed at an MDM was low at 29\% (234 of 797 with available data), similar to New Zealand, but has increased to $49 \%$ more recently. ${ }^{13,16}$
Patients whose cases were discussed at an MDM were more likely to be treated and had significantly better survival. Although cases that were discussed had a number of good prognostic features, on multivariate analysis (rerun with MDM added), discussion at an MDM was an independent prognostic factor for survival. Other researchers have identified more frequent active treatment ${ }^{17}$ as well as improved survival ${ }^{13}$ associated with discussion at an MDM. However, our data indicating that the survival benefit is maintained in both a landmark and a multivariate analysis provide a strong rationale for all cases to be discussed at an MDM.

The use of PET scan staging in about $43 \%$ (283 of 655 ) of all and $80 \%$ (158 of 198 [comprising 97 of 125 surgical patients and 61 of 97 patients treated with radiotherapy]) of curative NSCLC cases was considerably higher than in NSW. ${ }^{10}$ PET scans are particularly useful in mediastinal staging and identifying unrecognised metastases. ${ }^{6}$ Despite about 26\% of patients with NSCLC having Stage III disease, only around $8 \%$ (51 of 655 ) had invasive staging of the mediastinum, suggesting that some who underwent surgery or radiotherapy were inadequately staged.

Around $30 \%$ of patients with NSCLC underwent treatment with curative intent, including $19.1 \%$ going to surgery, which is a higher proportion than in NSW, New Zealand and the UK. ${ }^{10,13,14}$ Adjuvant chemotherapy rates were very low despite trials supporting adjuvant chemotherapy having just been reported at conferences by $2003 .{ }^{18}$ Overall, around 11\% of patients with NSCLC underwent radiotherapy with curative intent, with about $73 \%$ (53 of 73 with available data) being given as concurrent chemoradiation, which is the standard of care. ${ }^{8}$

The use of both chemotherapy ${ }^{19}$ and radiotherapy ${ }^{20}$ was low, although higher than in NSW. ${ }^{10}$ Over $21 \%$ of patients diagnosed with NSCLC received no treatment at all, which is of concern, although this rate was lower than that in $\mathrm{NSW}^{10}$ and the UK. ${ }^{14}$ We have not analysed this group closely but as more effective therapies with low toxicity (eg, epidermal growth factor receptor inhibi- tors) become available, it is likely that many patients will be suitable for molecular therapies despite not being suitable for chemotherapy.

As expected, around a third of patients with SCLC had limited stage disease, and most were treated with curative intent. These patients generally received chemotherapy along with thoracic radiotherapy, which is standard of care. ${ }^{21}$

It has been widely reported that outcomes for patients with lung cancer Australia who live outside major metropolitan centres are worse, ${ }^{2}$ but we did not see any significant difference in this study after adjusting for age and sex. However, on multivariate analysis, survival was significantly worse for two of the regional/rural cancer networks. These data would need to be confirmed by an analysis covering a longer time period, as the annual number of cases was small.

As in many other developed countries, the proportion of women with lung cancer increased over the decade from 1993 to 2003 while the proportion of patients with SCLC continued to decrease and, for patients with NSCLC, adenocarcinoma became more frequent than squamous cell carcinoma. The age of patients diagnosed with lung cancer increased by almost 3 years, considerably more than for other cancers. This may have been due to changing smoking habits, with patients in the more recent cohorts having not smoked as heavily as those in earlier cohorts, while this reduced intensity of tobacco exposure was associated with a later onset of the malignancy. ${ }^{22}$ The use of PET scanning increased considerably while the proportion of patients with NSCLC undergoing surgery with curative intent dropped by $6.2 \%$ (Box 5). It is likely that PET scanning prevented some patients going to surgery by identifying occult mediastinal or metastatic disease, with no detriment to survival. The use of combination chemoradiotherapy was much more frequent in 2003 than a decade earlier, in line with guidelines and best practice. $^{8}$ On the other hand, pathologically confirmed staging of the mediastinum was infrequent. Since 2003, imaging and biopsy by endobronchial ultrasound has become more widely available, obviating the 
need for mediastinoscopy for many patients. ${ }^{23}$

Although we did not identify a change in crude survival over the decade, statewide data for all Victorian patients with lung cancer over 2 decades have identified a steady improvement in 5-year relative survival from $9 \%$ in $1991-1995$ to $11 \%$ in 2001-2005 and 14\% for 2006-2010 (and 20\% for patients with NSCLC). ${ }^{24}$ Relative survival refers to the survival detriment compared with the age matched population without lung cancer.

Our approach in this survey, where we analysed a cohort followed for 5 years, means that our findings may not represent current practice. In light of this, a lung cancer registry has recently been established in Victoria, where cases are identified at diagnosis and data are collected prospectively.

Lung cancer survival clearly remains very poor, and although some progress has been made in better staging and greater use of multimodality therapy, our study has identified several areas that require improved patient management. These include increasing the proportions of patients who receive tissue diagnoses, receive active treatment, have PET scans (if curable), and receive postsurgical adjuvant chemotherapy. Of critical importance, our data support all cases of lung cancer being discussed at an MDM, which appears to be associated with a survival advantage. However, it is important to recognise that despite these measures, twothirds of patients will continue to present with incurable disease. Besides tobacco control, early diagnosis is crucial, and this may be achieved by measures such as screening of smokers by low radiation dose computed tomography scanning. ${ }^{25}$

Competing interests: No relevant disclosures.

Received 18 Mar 2013, accepted 28 Sep 2013.

1 Australian Institute of Health and Welfare. Cancer in Australia: an overview, 2008. Canberra: AlHW, 2008. (AlHW Cat. No. CAN 42; Cancer Series No. 46.)

2 Australian Institute of Health and Welfare, Australasian Association of Cancer Registries. Cancer in Australia: an overview 2012. Canberra: AlHW, 2012. (AlHW Cat No. CAN 70; Cancer Series No 74.)

3 Coleman MP, Forman D, Bryant $\mathrm{H}$, et al. Cancer survival in Australia, Canada, Denmark, Norway, Sweden, and the UK, 1995-2007 (the International Cancer Benchmarking Partnership): an analysis of population-based cancer registry data. Lancet 2011; 377: 127-138.

4 Richardson GE, Thursfield VJ, Giles GG. Reported management of lung cancer in Victoria in 1993: comparison with best practice. Anti-Cancer Council of Victoria Lung Cancer Study Group. Med J Aust 2000; 172: 321-324.

5 Ball DL, Irving LB. Are patients with lung cancer the poor relations in oncology? [comment] Med J Aust 2000; 172: 310-311.

6 Mac Manus MP, Hicks RJ, Ball DL, et al. F-18 fluorodeoxyglucose positron emission tomography staging in radical radiotherapy candidates with nonsmall cell lung carcinoma: powerful correlation with survival and high impact on treatment. Cancer 2001; 92: 886-895.

7 Pignon JP, Tribodet H, Scagliotti GV, et al. Lung adjuvant cisplatin evaluation: a pooled analysis by the LACE Collaborative Group. J Clin Oncol 2008; 26: 3552-3559.

8 Aupérin A, Le Péchoux C, Rolland E, et al. Metaanalysis of concomitant versus sequential radiochemotherapy in locally advanced nonsmall-cell lung cancer.J Clin Oncol 2010; 28: 2181-2190.

9 Colinet B, Jacot W, Bertrand D, et al. A new simplified comorbidity score as a prognostic factor in non-small-cell lung cancer patients: description and comparison with the Charlson's index. Br J Cancer 2005; 93: 1098-1105.

10 Vinod SK, O'Connell DL, Simonella L, et al. Gaps in optimal care for lung cancer. I Thorac Oncol 2008; 3: 871-879.

11 Longo DL, Fauci AS, Kasper DL, et al. Harrison's principles of internal medicine. 18th ed. Sydney: McGraw Hill Medical, 2013: 55.

12 Coory M, Fong K, Bowman R, Hall L. Why we need a population-based approach to clinical indicators for cancer: a case study using microscopic confirmation of lung cancer in Queensland. Intern Med J 2006; 36: 389-392.
13 Stevens W, Stevens G, Kolbe J, Cox B. Lung cancer in New Zealand: patterns of secondary care and implications for survival. J Thorac Oncol 2007; 2: 481-493.

14 Health and Social Care Information Centre, National Lung Cancer Audit. National Lung Cancer Audit Report 2012. Leeds, UK: HSCIC, 2012. http://www.hqip.org.uk/assets/NCAPOPLibrary/NCAPOP-2012-13/Lung-CancerNational-Audit-Report-pub-2012.pdf (accessed Sep 2013).

15 Gregor A, Thomson CS, Brewster DH, et al. Management and survival of patients with lung cancer in Scotland diagnosed in 1995: results of a national population based study. Thorax 2001; 56: 212-217.

16 Department of Health. Cancer Service Performance Indicators Report 2012. Melbourne: State Government of Victoria, 2012.

17 Boxer MM, Vinod SK, Shafiq J, Duggan KJ. Do multidisciplinary team meetings make a difference in the management of lung cancer? Cancer 2011; 117: 5112-5120.

18 Arriagada R, Bergman B, Dunant A, et al; International Adjuvant Lung Cancer Trial Collaborative Group. Cisplatin-based adjuvant chemotherapy in patients with completely resected non-small-cell lung cancer.N Engl J Med 2004; 350: 351-360.

19 Jacob S, Hovey E, Ng W, et al. Estimation of an optimal chemotherapy utilisation rate for lung cancer: an evidence-based benchmark for cancer care. Lung Cancer 2010; 69: 307-314.

20 Delaney G, Barton M, Jacob S, Jalaludin B. A model for decision making for the use of radiotherapy in lung cancer. Lancet Oncol 2003; 4: $120-128$.

21 Pignon JP, Arriagada R, Inde DC, et al. A metaanalysis of thoracic radiotherapy for small-cell lung cancer. N Engl J Med 1992; 327: 1618-1624.

22 Adair T, Hoy D, Dettrick Z, Lopez AD. Reconstruction of long-term tobacco consumption trends in Australia and their relationship to lung cancer mortality. Cancer Causes Control 2011; 22: 1047-1053.

23 Steinfort DP, Hew MJ, Irving LB. Bronchoscopic evaluation of the mediastinum using endobronchial ultrasound: a description of the first 216 cases carried out at an Australian tertiary hospital. Intern Med J 2011; 41: 815-824.

24 Cancer Council Victoria. Cancer Survival Victoria 2012. Melbourne: Cancer Council Victoria, 2012: 36. www.cancervic.org.au/downloads/cec/ cancer-survival-victoria-2012.pdf (accessed Sep 2013).

25 The National Lung Screening Trial Research Team. Reduced lung-cancer mortality with lowdose computed tomographic screening. $N$ Eng / J Med 2011; 365: 395-409. 